\title{
Clinical study of a survivin long peptide vaccine (SurVaxM) in patients with recurrent malignant glioma
}

\author{
Robert A. Fenstermaker ${ }^{1,5,7} \cdot$ Michael J. Ciesielski ${ }^{1,5}$ () Jingxin Qiu $^{2} \cdot$ Nuo Yang $^{1,8}$ • \\ Cheryl L. Frank ${ }^{1} \cdot$ Kelvin P. Lee $^{5,7} \cdot$ Laszlo R. Mechtler $^{3} \cdot$ Ahmed Belal $^{4}$. \\ Manmeet S. Ahluwalia ${ }^{8} \cdot$ Alan D. Hutson ${ }^{6}$
}

Received: 18 May 2016 / Accepted: 17 August 2016/ Published online: 30 August 2016

(C) The Author(s) 2016. This article is published with open access at Springerlink.com

\begin{abstract}
Survivin is an anti-apoptotic protein that is highly expressed in many cancers, including malignant gliomas. Preclinical studies established that the conjugated survivin peptide mimic SurVaxM (SVN53-67/M57$\mathrm{KLH}$ ) could stimulate an anti-tumor immune response against murine glioma in vivo, as well as human glioma cells ex vivo. The current clinical study was conducted to test safety, immunogenicity and clinical effects of the vaccine. Recurrent malignant glioma patients whose tumors were survivin-positive, and who had either HLA-A*02 or HLA-A*03 MHC class I allele-positivity, were given subcutaneous injections of SurVaxM $(500 \mu \mathrm{g})$ in Montanide ISA 51 with sargramostim $(100 \mu \mathrm{g})$ at 2-week intervals. SurVaxM was well tolerated with mostly grade one adverse events (AE) and no serious adverse events (SAE)
\end{abstract}

Robert A. Fenstermaker

robert.fenstermaker@ roswellpark.org

1 Department of Neurosurgery, Roswell Park Cancer Institute, Elm and Carlton Streets, Buffalo, NY 14263, USA

2 Department of Pathology, Roswell Park Cancer Institute, Elm and Carlton Streets, Buffalo, NY 14263, USA

3 Department of Neuro-Oncology, Roswell Park Cancer Institute, Elm and Carlton Streets, Buffalo, NY 14263, USA

4 Department of Diagnostic Imaging, Roswell Park Cancer Institute, Elm and Carlton Streets, Buffalo, NY 14263, USA

5 Department of Immunology, Roswell Park Cancer Institute, Elm and Carlton Streets, Buffalo, NY 14263, USA

6 Department of Biostatistics, Roswell Park Cancer Institute, Elm and Carlton Streets, Buffalo, NY 14263, USA

7 Center for Immunotherapy, Roswell Park Cancer Institute, Elm and Carlton Streets, Buffalo, NY 14263, USA

8 Burkhardt Brain Tumor and Neuro-Oncology Center, Cleveland Clinic Foundation, Cleveland, OH 44195, USA attributable to the study drug. Six patients experienced local injection site reactions; three patients reported fatigue (grades 1 and 2), and 2 patients experienced myalgia (grade 1). Six of eight immunologically evaluable patients developed both cellular and humoral immune responses to vaccine. The vaccine also stimulated HLA-A*02, HLA-A*03 and HLA-A*24 restricted $\mathrm{T}$ cell responses. Three patients maintained a partial clinical response or stable disease for more than 6 months. Median progression-free survival was 17.6 weeks, and median overall survival was 86.6 weeks from study entry with seven of nine patients surviving more than 12 months.

Keywords Apoptosis · Glioma - Immunotherapy · Peptide $\cdot$ Survivin $\cdot$ Vaccine

$\begin{array}{ll}\text { Abbreviations } \\ \text { AE } & \text { Adverse event } \\ \text { BIRC5 } & \text { Survivin } \\ \text { CFSE } & \text { Carboxyfluorescein succinimidyl ester } \\ \text { CR } & \text { Complete response } \\ \text { CTCAE } & \text { Common terminology criteria for adverse } \\ & \text { events } \\ \text { CTL } & \text { Cytotoxic T lymphocytes } \\ \text { GAPDH } & \text { Glyceraldehyde-3-phosphate dehydrogenase } \\ \text { GM-CSF } & \text { Granulocyte macrophage-colony stimulating } \\ & \text { factor, sargramostim } \\ \text { HBSS } & \text { Hank's balanced salt solution } \\ \text { IAP } & \text { Inhibitor of apoptosis protein } \\ \text { KLH } & \text { Keyhole limpet hemocyanin } \\ \text { KPS } & \text { Karnofsky performance status } \\ \text { OS } & \text { Overall survival } \\ \text { PFS } & \text { Progression free survival } \\ \text { PR } & \text { Partial response } \\ \text { RLT } & \text { Regimen-limiting toxicity } \\ & \end{array}$


RPCI Roswell Park Cancer Institute

SAE Serious adverse event

SD Stable disease

TCGA The Cancer Genome Atlas

\section{Introduction}

Survivin (BIRC5) is a member of the inhibitor of apoptosis protein (IAP) family [1, 2]. Survivin expression in tumors is associated with a high rate of disease recurrence and resistance to chemotherapy, and it confers a significant survival advantage to tumor cells [3]. Its presence in gliomas and other tumors is reportedly associated with a poor prognosis [4]. It is expressed in all four subtypes of glioblastoma defined by The Cancer Genome Atlas (TCGA) project, including: classical, mesenchymal, neural and proneural variants [5].

Although expressed during fetal development [2], survivin is infrequently detected in the normal tissues of adult organisms [6]. Thus, the molecule represents a potential target for cancer immunotherapy. One immunohistochemical study of gliomas demonstrated that 29 of 29 glioma specimens (WHO grades II-IV), but not normal brain tissue, contain survivin-positive cells [7]. The mean percentage of cells detectable by immunohistochemical methods in each specimen was $70.0 \%$ in grade II (low grade) gliomas, $81.3 \%$ in grade III (anaplastic) gliomas and $85.0 \%$ in grade IV gliomas (glioblastoma). Survivin is also present in association with plasma-derived exosomes of glioma patients in which its action remains to be defined [8].

As a largely intracellular protein, survivin is degraded by the proteasome and resulting epitopes are presented on the surface of tumor cells by MHC class I molecules. Accordingly, survivin-specific cytotoxic $\mathrm{T}$ lymphocytes (CTL) have been identified in some cancer patients $[9,10]$. In addition to $\mathrm{T}$ cell-mediated immunity, many cancer patients develop humoral immune responses to survivin with antisurvivin antibodies detectable in serum [10]. Therefore, survivin is potentially immunogenic and such responses as these could provide the basis for induction of therapeutic anti-tumor immunity in cancer patients in whom the immune system is already primed to recognize survivin.

SurVaxM (SVN53-67/M57-KLH) contains a synthetic long peptide mimic that spans amino acids 53 through 67 of the human survivin protein sequence [11]. The amino acid alteration in this peptide (M57) leads to enhanced binding of the core survivin epitope to HLA-A*0201 molecules [11]. The peptide is conjugated to keyhole limpet hemocyanin $(\mathrm{KLH})$, which acts as a vaccine adjuvant. The long peptide also contains multiple MHC class I epitopes that are presentable by other HLA molecules. In addition, the long peptide is able to stimulate specific $\mathrm{CD}^{+}$cytokine support $[11,12]$. The presence of MHC class II-restricted
$\mathrm{CD}^{+} \mathrm{T}$ cells that are specific for tumor-associated antigens has been recognized as an important element for providing helper factors essential for eliciting and sustaining cytotoxic $\mathrm{CD}^{+}$responses against tumors $[13,14]$.

\section{Patients and methods}

\section{Study overview}

This clinical study (clinicaltrials.gov identifier NCT01250470) was conducted in patients with HLA-A*02 and HLA-A*03 haplotypes who had histologically confirmed survivin-positive malignant gliomas that had recurred or progressed following standard therapy, including surgery, fractionated radiation therapy and chemotherapy with temozolomide. It was designed to test the toxicity (primary outcome) and immunogenicity (secondary outcome) of SurVaxM in emulsion with Montanide ISA 51 and given subcutaneously with sargramostim (GM-CSF) as a dendritic cell attractant and maturant. This was a nonrandomized, single-institution, clinical trial designed to assess a fixed dose vaccine regimen. Based on pre-clinical toxicity studies, a dose level of $500 \mu \mathrm{g}$ SurVaxM was selected for testing. A regimen of four prime-boost doses at this level was given without dose escalation. In order to test the response to extended dosing, patients that survived 6 months without disease progression or regimen-limiting toxicity were eligible to receive additional booster doses of vaccine. The use of SVN53-67/M57-KLH in this study is registered with the USFDA under IND \#14674 held by Roswell Park Cancer Institute (RPCI). The composition of SVN53-67/M57-KLH (SurVaxM) has been previously described [11]. All investigations were performed under a clinical protocol approved by the institutional review board at RPCI and in accordance with an assurance filed with and approved by the US Department of Health and Human Services. Informed consent was obtained from each subject prior to treatment.

\section{Patient eligibility}

Inclusion criteria were: age $\geq 18$ years, histologic proof of recurrent or progressive glioblastoma, anaplastic astrocytoma, anaplastic oligodendroglioma or anaplastic mixed glioma following failure of standard therapy, Karnofsky performance status (KPS) $\geq 70$, HLA-A $* 02$ or HLA-A $* 03$ haplotype, survivin expression by tumor cells documented by immunohistochemistry, no systemic infection or ongoing antibiotic therapy, white blood cell count $\geq 3000 /$ $\mathrm{mm}^{3}$, platelets $\geq 100,000 / \mathrm{mm}^{3}$, hemoglobin $\geq 10.0 \mathrm{~g} / \mathrm{dL}$, AST(SGOT)/ALT(SGPT) $<2.5 \times \mathrm{ULN}$, total bilirubin $\leq 2.0 \mathrm{mg} / \mathrm{dL}$ and serum creatinine $\leq 1.5 \times$ ULN. Patients with potential for child-bearing were required to agree to the use of acceptable contraceptive methods during treatment and for 3 months after receiving the last dose of 
vaccine, patients who had had recent cranial surgery were eligible for inclusion, but the vaccine could not be administered prior to the 14 th post-operative day.

\section{Treatment plan}

Nine patients were treated with SurVaxM $(500 \mu \mathrm{g})$ in emulsion with Montanide ISA 51 with sargramostim $(100 \mu \mathrm{g})$ every 2 weeks for a total of four doses per patient (primeboost phase). All patients in each group were followed for at least 6 weeks before the next group of three patients could begin treatment to limit the total number of individuals exposed to possible toxicity. The dose of vaccine was not escalated in an individual patient or between cohorts. Patients were followed clinically every 2 weeks for the first 8 weeks and then monthly until tumor progression or death. Patients were assessed for regimen-limiting toxicity (RLT) using CTCAEv4.0 criteria (see definition of RLT below). Clinical responses were ascertained by neurologic exams on schedule and from serial MRI brain scans. Patients who survived 6 months without tumor progression, RLT or serious adverse event (SAE) were eligible to receive additional doses of the vaccine every 3 months (booster phase).

\section{Evaluation during study}

The primary goal of this study was to assess the safety, tolerability and toxicity of the survivin peptide mimic vaccine regimen. A secondary goal was to measure immune responses to the vaccine, including anti-survivin antibody production, survivin-specific multimer immunoreactivity and IFN $\gamma$ mRNA production following vaccination. Tertiary goals were to measure tumor progression after vaccination, identify any apparent treatment responses and measure survival. Safety was assessed by physical and neurological examinations and laboratory studies.

MRI brain scans were performed serially, and established criteria were used to determine radiographic response for those with measureable disease. Response categories included: (1) complete response (CR), disappearance of all enhancing tumor on consecutive MRI scans at least 1 month apart, off steroids, and neurologically stable or improved; (2) partial response (PR), $50 \%$ reduction in size of enhancing tumor on consecutive MRI scans at least 1 month apart, steroids stable or reduced, and neurologically stable or improved; (3) progressive disease (PD), $>25 \%$ increase in size of enhancing tumor or any new tumor on MRI scans, or neurologically worse, and steroids stable or increased; and (4) stable disease (SD), all other situations. The measure of tumor size is the largest cross-sectional diameter multiplied by the largest diameter perpendicular to it. Progression-free survival (PFS) is defined as the duration of time from study entry to progression on MRI or death.

\section{Clinical evaluability}

Patients who received at least one dose of vaccine were considered evaluable for the purpose of determining toxicity. Patients who received $\geq 2$ doses of vaccine were deemed evaluable for immunological response; however, those who did not receive $\geq 2$ doses were not replaced (patient \#4). Patients who received $\geq 3$ doses of vaccine and had an MRI scan 8 weeks following initiation of therapy were considered evaluable for clinical response. Patients who were unevaluable for clinical response were not replaced (patient \#4).

\section{Safety}

NCI common terminology criteria for adverse events (CTCAEv4.0) were used to evaluate toxicity. Toxicity was considered to be an adverse event possibly, probably or definitely related to treatment. The maximum grade of toxicity for each category of interest was recorded for each patient, and the summary results were tabulated by category and grade. Regimen-limiting toxicities (RLT) were defined to include: (1) any grade 3 or greater toxicity possibly, probably or definitely related to the vaccine, (2) any grade 2 or greater autoimmune disorder, (3) any grade 2 or greater allergic reaction and (4) any peptide vaccine dosing delay $>2$ weeks.

\section{Survival}

All patients were followed to ascertain both progressionfree survival (PFS) and median overall survival (OS).

\section{Immunohistochemical studies}

Immunohistochemical detection of survivin was performed using a Dako Omnis autostainer (Dako North America, Inc. Carpinteria, CA) with rabbit monoclonal survivin antibody clone EP119 (Bio SB, Santa Barbara, CA). Additional antibodies included: CD4 (4B12, Dako); CD8 (C8/144B, Dako); CD20 (L26, Dako); PD-L1/CD274 (SP142, Spring Bioscience). Stained specimens were viewed by the neuropathologist, co-investigator (JQ), and survivin expression in the nucleus and cytoplasm was determined to be present or absent.

\section{Immunologic assessments}

\section{Serum antibody measurements}

Patient serum was collected and stored at $-80{ }^{\circ} \mathrm{C}$. Serial dilutions of clarified serum were applied to unconjugated survivin peptide, free KLH and random peptide $(20 \mu \mathrm{g} / \mathrm{ml}, 1 \mu \mathrm{g} / \mathrm{well})$ on pre-coated ELISA plates (Flat Bottom, Nunc) in triplicate. 
Samples were incubated at $4{ }^{\circ} \mathrm{C}$ overnight and washed (PBS, $1 \%$ BSA). HRP-conjugated anti-human IgG detection antibody (Bio-Rad) was added for $1 \mathrm{~h}$ at $25{ }^{\circ} \mathrm{C}$. Plates were washed four times, and TMB colorimetric solution (Biolegend) was added at room temperature and developed for $15 \mathrm{~min}$ and read on a Bio-Rad automated plate reader at $450 \mathrm{~nm}$.

\section{PBMC isolation}

Peripheral blood mononuclear cells were isolated within $3 \mathrm{~h}$ from blood samples using Ficoll separation technique. Heparinized blood was diluted (1:1) with Hank's balanced salt solution (HBSS) (Mediatech, Cat\#: 21-023-CV). Blood/HBSS diluent was layered on top of lymphocyte separation medium (LSM; Mediatech, Cat\#: 25-072-CV) in 50 -ml conical tubes. Tubes were centrifuged at $400 \times g$ for $30 \mathrm{~min}$. PBMC layer was centrifuged at $600 \times \mathrm{g}$ for $10 \mathrm{~min}$. Cell pellets were re-suspended in $5 \mathrm{ml}$ of CTL wash solution (Cat\#: CTLW010)/RPMI (Mediatech, Cat\#: 10-040CV) solution. The pooled sample was centrifuged at $500 \times g$ for $5 \mathrm{~min}$, and the pellet was re-suspended in freezing media (10\% DMSO/90 \% fetal bovine serum) and transferred to liquid nitrogen storage.

\section{Multimer analysis}

Custom-designed multimers included the following: MHC Dextramer-PE (Immudex, Copenhagen, Denmark) to A*0201:QMFFCFKEL; A*0301:AQMFFCFK; $A * 0301: D L A Q M F F C F K ; A * 0301: L A Q M F F C F K$; as well as iTag-PE Tetramer (BD Coulter) to A*0201:AQMFFCFKEL; and $A * 24: D L A Q M F F C F$. Control represents results with a nonsense Dextramer (Immudex). Patient PBMC were washed in PBS and re-suspended at a concentration of $1 \times 10^{6}$ cells/ ml. $50 \mu \mathrm{l}$ of sample was added to each well of a round bottom 96 well plate (Costar), and $5 \mu$ of FcR Block reagent was incubated with cells at room temperature for $10 \mathrm{~min} .10 \mu \mathrm{l}$ of MHC Dextramer or iTag-PE Tetramer was added. The plate was vortexed and incubated for $20 \mathrm{~min}$ at room temperature in the dark. Following incubation, $10 \mu \mathrm{l}$ anti-CD8-FITC $(500 \mu \mathrm{g} / \mathrm{ml}$ clone $\mathrm{T} 8$; BD Coulter) was added, mixed and incubated for $30 \mathrm{~min}$ at room temperature. Cells were washed and re-suspended in PBS-fluorofix buffer $(0.5 \%$ paraformaldehyde). Data acquisition was obtained using a Fortessa flow cytometer running FACSDiva software. Data analysis was performed using FCS Express software. Results are based upon gating of $\mathrm{CD} 8^{+} \mathrm{T}$ cells and indicate the percent of cells positively labeled with specific tetramer.

\section{T cell proliferation}

PBMC were tested for peptide-specific proliferation as previously described [15]. PBMC were labeled with carboxyfluorescein succinimidyl ester (CFSE) and stimulated ex vivo with SVN53-67/M57 or control peptide (100 ng/ml over $48 \mathrm{~h}$ ). Cells were stained for CD4 or CD8 and data acquired via FACS analysis and FCS Software as described above.

\section{$C D 4^{+}$and $C D 8^{+}$separation}

SureBeadsTM Protein G Magnetic Beads (Cat. 161-4023, Bio-Rad Laboratories, Inc.) were incubated with either LEAF CD8a (clone RPA-T8, Cat. 301018, BioLegened) or LEAF CD4 (clone OKT4, Cat. 317404, BioLegened). The antibody-bound magnetic beads were then incubated

Table 1 Patient characteristics

\begin{tabular}{|c|c|c|c|c|c|c|c|c|c|c|}
\hline Patient & HLA-A* & & Age & Sex & Tumor $^{\mathrm{a}}$ & Number of recurrences & Disease burden ${ }^{b}$ & Prior treatments ${ }^{\mathrm{c}}$ & Priming doses & Booster doses \\
\hline 1 & 01 & 03 & 38 & $\mathrm{M}$ & G1 & 1 & + & $\mathrm{S}, \mathrm{R}, \mathrm{T}, \mathrm{S}$ & 4 & + \\
\hline 2 & 01 & 02 & 45 & $\mathrm{~F}$ & $\mathrm{G} 2$ & 2 & +++ & $\mathrm{S}, \mathrm{R}, \mathrm{T}, \mathrm{S} / \mathrm{C}, \mathrm{B}, \mathrm{SR}$ & 4 & - \\
\hline 3 & 02 & 24 & 52 & $\mathrm{~F}$ & G2 & 1 & + & $\mathrm{S}, \mathrm{R}, \mathrm{T}, \mathrm{S}$ & 4 & - \\
\hline 4 & 01 & 02 & 34 & M & G2 & 3 & +++ & $\mathrm{S}, \mathrm{R}, \mathrm{T}, \mathrm{SR}, \mathrm{S}, \mathrm{B}, \mathrm{O}$ & $2^{\mathrm{d}}$ & - \\
\hline 5 & 02 & 24 & 58 & M & $\mathrm{G} 2$ & 2 & + & $\mathrm{S}, \mathrm{R}, \mathrm{T}, \mathrm{B}, \mathrm{SR}$ & 4 & + \\
\hline 6 & 02 & 02 & 48 & $\mathrm{~F}$ & G1 & 1 & ++ & $\mathrm{S}, \mathrm{R}, \mathrm{T}, \mathrm{S}$ & 4 & - \\
\hline 7 & 02 & 02 & 57 & M & AG & 2 & + & $\mathrm{S}, \mathrm{R}, \mathrm{T}$ & 4 & + \\
\hline 8 & 01 & 02 & 61 & M & G1 & 1 & + & $\mathrm{S}, \mathrm{R}, \mathrm{T}, \mathrm{S}$ & 4 & - \\
\hline 9 & 02 & 24 & 54 & M & G2 & 1 & + & $\mathrm{S}, \mathrm{T}, \mathrm{S}, \mathrm{R}, \mathrm{T}, \mathrm{S}, \mathrm{SR}$ & 4 & - \\
\hline
\end{tabular}

${ }^{\text {a }} \mathrm{G} 1$, primary glioblastoma; G2, secondary glioblastoma; AG, anaplastic glioma

b Disease burden at first dosing: (-) no measureable contrast enhancement (C.E.); (+), measureable C.E., but $<1 \mathrm{~cm}^{3} ;(++),>1 \mathrm{~cm}^{3}$ but $\leq 5 \mathrm{~cm}^{3}$ C.E.; $(+++),>5 \mathrm{~cm}^{3}$ C.E

c $S$ surgery, $R$ fractionated radiation therapy, $S R$ stereotactic radiosurgery, $T$ temozolomide, $B$ bevacizumab, $O$ other chemotherapy, $C$ carmustine wafer implant

${ }^{\mathrm{d}}$ N.E., not evaluable for clinical response due to tumor progression prior to third priming dose of vaccine 
with $1 \times 10^{5}$ PBMC. After bead-based CD4/CD8 separation, fluorochrome-labeled antibodies to $\mathrm{CD} 8$ (clone RPA-T8, FITC, Cat. 301050, BioLegend) and CD4 (clone OKT4, PE/Cy5, Cat. 317412, BioLegend) were added to remaining PBMC. The samples were acquired and analyzed by FACS as above. Analysis was based upon isolated gating of lymphocyte populations with specific CD markers as indicated. Sample purity is based upon the percent of specific cells removed from the starting population.

\section{Cytokine mRNA isolation and quantification}

Patient samples $\left(1 \times 10^{5}\right.$ PBMC) were incubated with SVN53-67/M57 peptide at several concentrations (160$1600 \mathrm{ng} / \mathrm{ml}$ ) in OpTmizer CTS complete serum-free media (Gibco) overnight at $37{ }^{\circ} \mathrm{C}$ in 96 well plates. After incubation, $\mathrm{CD}^{+}$and $\mathrm{CD} 8^{+} \mathrm{T}$ cells were separated from total PBMC by magnetic beads. Anti-human CD4 antibody ( $5 \mu \mathrm{g}$; clone OKT4) or anti-human CD8 antibody (5 $\mu \mathrm{g}$; clone RPA-T8) (BioLegend, San Diego, CA) was added to Protein G Magnetic SureBeads (BioRad, San Diego, CA) and incubated for $60 \mathrm{~min}$ at room temperature with peptide-stimulated cells. Isolated cells were collected and washed in PBS. Total RNA was isolated from separated human $\mathrm{CD}_{4}^{+}$and $\mathrm{CD} 8^{+}$cells using the PureLink RNA Mini Kit (Life Technologies) according to manufacturer's instructions. RNA was reverse transcribed using Superscript Vilo Master Mix (Life Technologies). cDNA concentrations were determined using a Nanodrop 2000 Spectrophotometer (Thermo Scientific). RT-qPCR was performed using a 7900HT Fast Real-Time PCR System

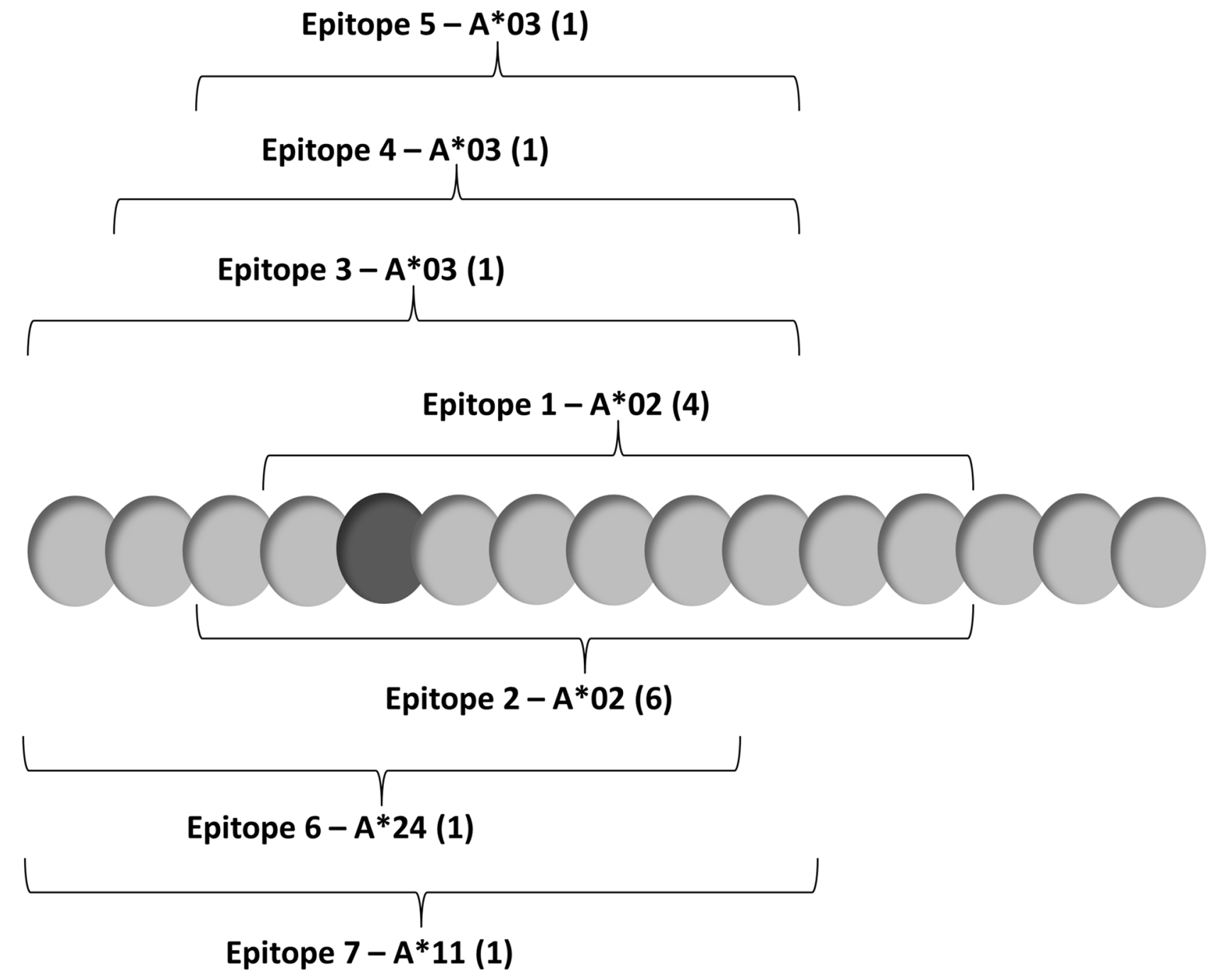

Fig. 1 Long survivin peptide contained in SVN53-67/M57-KLH is shown with brackets indicating empirically confirmed immuno-reactive HLA-A*02, HLA-A*03, HLA-A*11 and HLA-A*24 epitopes within it. The position of the cysteine-to-methionine substitution (mimic) within the peptide is indicated (dark gray) 


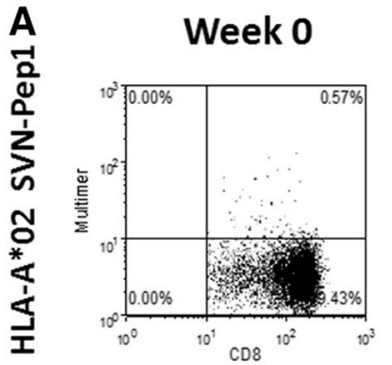

Week 4

Week 8

Week 12
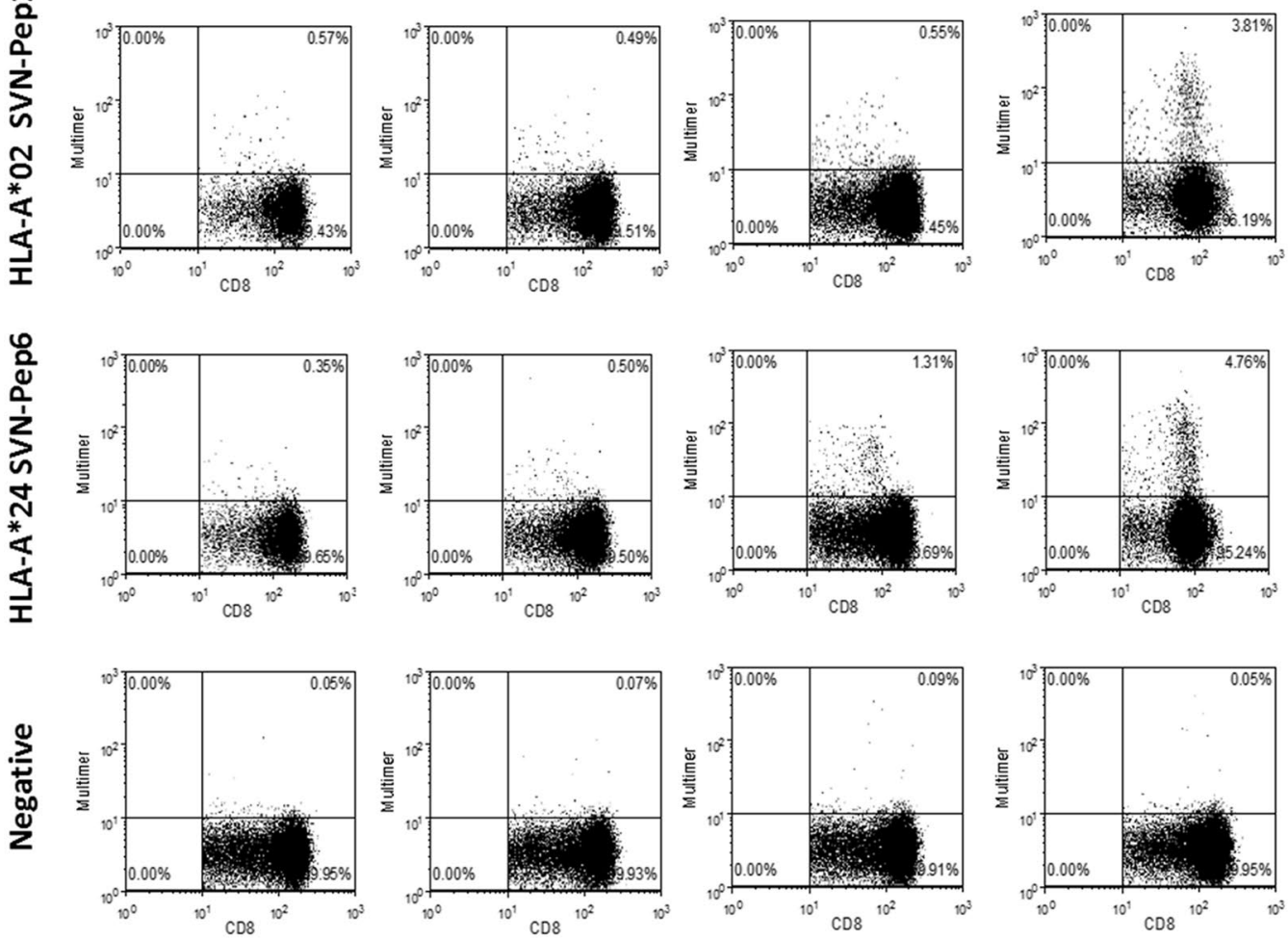

B
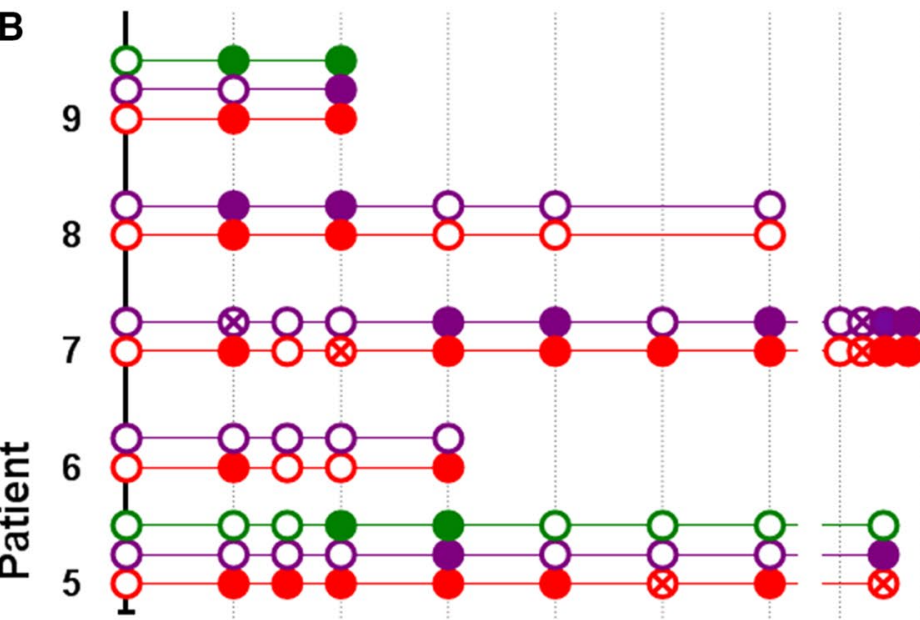

LLA-A*02 pep1

O HLA-A*02 pep2

O HLA-A*03 pep3

O HLA-A*03 pep4

O HLA-A*03 pep5

HLA-A*24 pep6

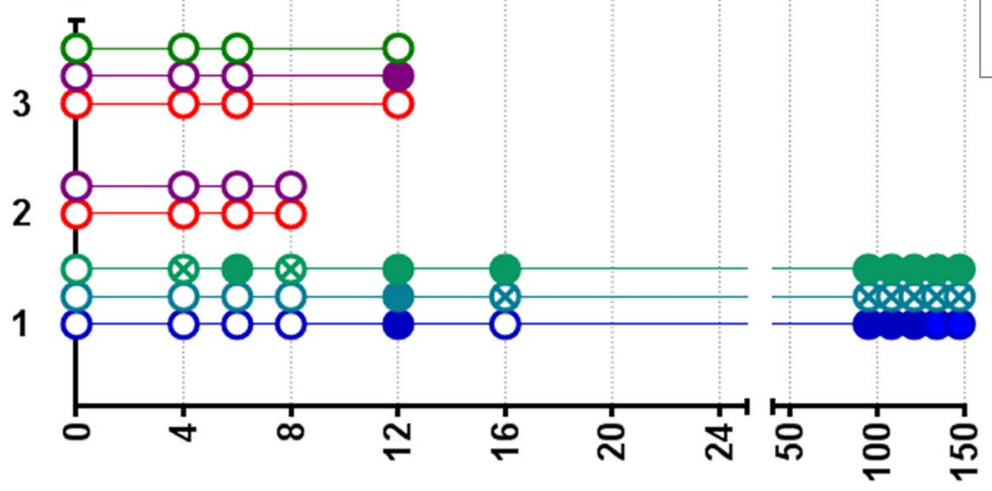

Weeks 
4Fig. 2 a FACS analysis of representative MHC class I dextramer assays of PBMC from a HLA-A*02/24 patient. Multimer binding of $\mathrm{CD}^{+} \mathrm{T}$ cells specific for survivin epitopes Pep1 and Pep6 (see Fig. 1) is shown. The upper right quadrant of each panel shows survivin multimer $+/ \mathrm{CD}^{+}$gated $\mathrm{T}$ cells. Week 0 is pre-immunization blood sampling. Control represents results with a nonsense dextramer. b Binding of multimers to $\mathrm{CD}^{+} \mathrm{T}$ cell receptors in patients measured at weeks $8-150$ following study entry. Data acquisition was performed by FACS analysis as revealed in a. Patient samples registering $\geq 1 \%$ over baseline survivin-specific $\mathrm{CD}^{+} \mathrm{T}$ cells are shown as (filled circle). Patients not mounting an immune response to a particular peptide are shown as (open circle). Weakly positive patients registering $\geq 0.75 \%$ and $<1 \%$ above baseline are (circled times). Custom-designed multimers included: Pep1, HLA-A*0201: QMFFCFKEL; Pep2, HLA-A*0201: AQMFFCFKEL; Pep3, HLA-A*0301: DLAQMFFCFK; Pep4, HLA-A*0301: LAQMFFCFK; Pep5, HLA-A*0301: AQMFFCFK; and Pep6; HLA-A*24: DLAQMFFCF. A negative control nonsense multimer was used to assess nonspecific binding. MHC Dextramer-PE (Immudex, Copenhagen, Denmark) to A*0201:QMFFCFKEL; A*0301:AQMFFCFK; A*0301:DLAQMFFCFK; $\quad A^{*} 0301: L A Q M F F C F K ; \quad$ as well as iTag-PE Tetramer (BD Coulter) to A*0201:AQMFFCFKEL; and A*24:DLAQMFFCF

(Life Technologies) with Power SYBR Green PCR Master Mix (Life Technologies). Primers for IFN $\gamma$ had the sequences: 5'-GCATCCAAAAGAGTGTGGAG-3' and 5'-ATGCTCTTCGACCTCGAAAC-3'. Glyceraldehyde3-phosphate dehydrogenase (GAPDH) mRNA was used as an internal control, and GAPDH primers had the following sequences: 5'-GGTGAAGGTCGGAGTCAACGG-3' and 5'-GAGGTCAATGAAGGGGTCATTG-3'. Reactions containing no cDNA were included in each run. Relative cytokine mRNA expression levels were calculated by the $\Delta \Delta C_{\mathrm{t}}$ method using RQ Manager software (Applied Biosystems). All samples were run in triplicate. The level of GAPDH gene expression served as an endogenous control. Data are represented as the ratio of the target gene/GAPDH normalized to unstimulated cells. Total mRNA values were expressed relative to PBMC RNA. An unpaired t test with Welch's correction was applied to all of the data sets.

\section{Results}

\section{Patient characteristics}

Patient characteristics are listed in Table 1. All patients had previously undergone treatment, including: surgical resection, fractionated external beam radiation therapy and chemotherapy with temozolomide. Every patient had recurrent or progressive disease following failure of standard therapy at the time of entry. Five of nine patients were entered in the trial at first recurrence, and four patients were entered after two or more recurrences. Other previous treatments are listed in Table 1. Eight patients received the full complement of four priming doses of vaccine, and three patients received at least one booster dose in an extended dosing phase as well. One patient was not clinically evaluable due to rapid progression after the second dose of vaccine.

\section{Adverse events (AE) and toxicity}

All nine patients were evaluable for the purposes of determining toxicity. SurVaxM demonstrated a good tolerability profile with no serious adverse events (SAE) during the prime-boost phase of up to four doses. The majority of AEs were grade one. Six of nine patients experienced at least one injection site reaction (all grade one) with localized erythema likely related to the vaccine components. Three patients reported fatigue (grades 1 or 2). Two patients experienced myalgias, probably related to the study regimen. Grade 1 lymphopenia was seen in three patients and leukopenia in three patients (grades 1 and 2). The only grade $3 \mathrm{AE}$, a seizure, was not related to the vaccine. During the extended dosing phase, one patient suffered acute renal failure (SAE) due to gabapentin toxicity with complete resolution following intravenous hydration. Renal biopsy showed no inflammatory tubular changes, immune complex deposition, glomerulonephritis or other evidence of immunologic toxicity.

\section{T cell responses}

Individual epitopes contained within the long peptide are shown in Fig. 1. Survivin-specific T cell responses to vaccine were measured using synthetic MHC-peptide complexes (multimers) to $\mathrm{CD}^{+} \mathrm{T}$ cell receptors at baseline and after vaccination (Fig. 2a). Patient samples registering $\geq 1 \%$ over baseline survivin-specific $\mathrm{CD}^{+} \mathrm{T}$ cells were recorded as positive (Fig. 2b). Values that registered $\geq 0.75$ and $<1 \%$ above baseline were recorded as being weakly positive. Patients not mounting an immune response $(<0.75 \%)$ to at least one relevant peptide were recorded as being negative. Patients generally developed a measureable immune response beginning 8-12 weeks after initial vaccination. Two of three patients in the 3-month booster group experienced an increase in multimer-reactive $\mathrm{CD}^{+} \mathrm{T}$ cells over a period of 50-150 weeks, suggestive of established immune memory. In addition to HLA-A*02 and HLAA*03 status, three patients had HLA-A*24 alleles permitting multimer analysis of HLA-A*24-restricted responses to vaccine. Two of three such patients had responses to the vaccine from both alleles.

\section{Humoral immune responses}

IgG antibodies to epitopes within the survivin peptide (Fig. 3a) and to the corresponding wild-type survivin 


\section{A anti-SVN53-67/M57 IgG}
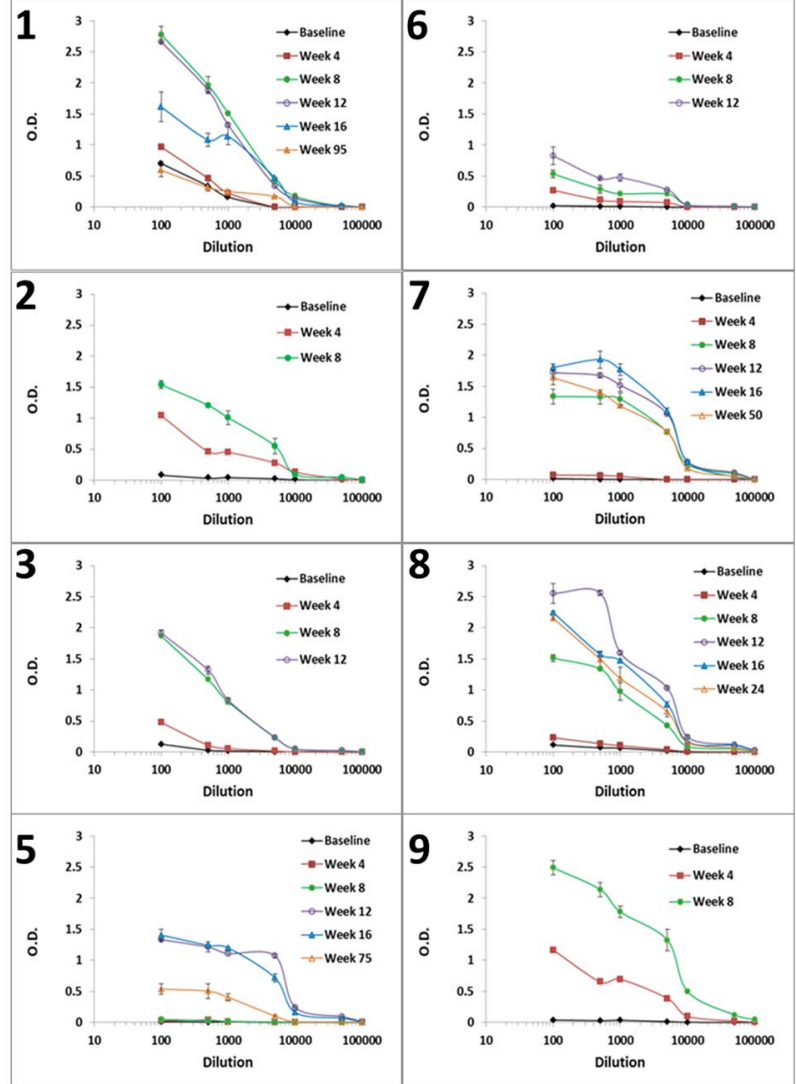

\section{C}
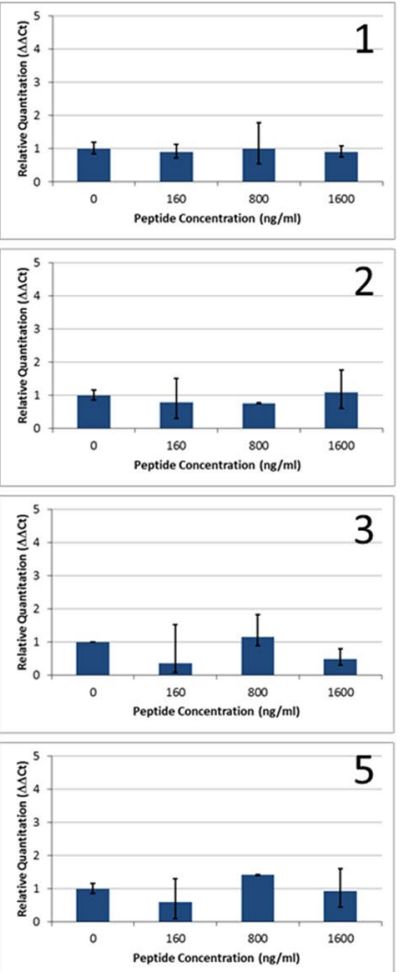

CD4+
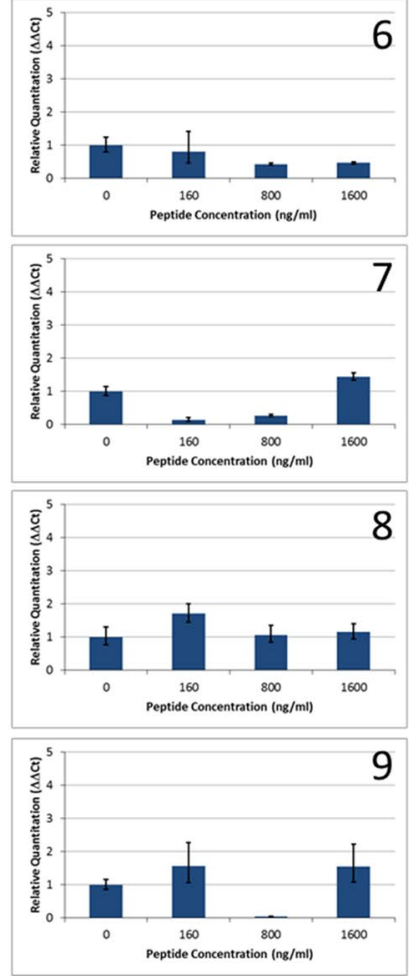

B anti-SVN53-67 (wild type) IgG
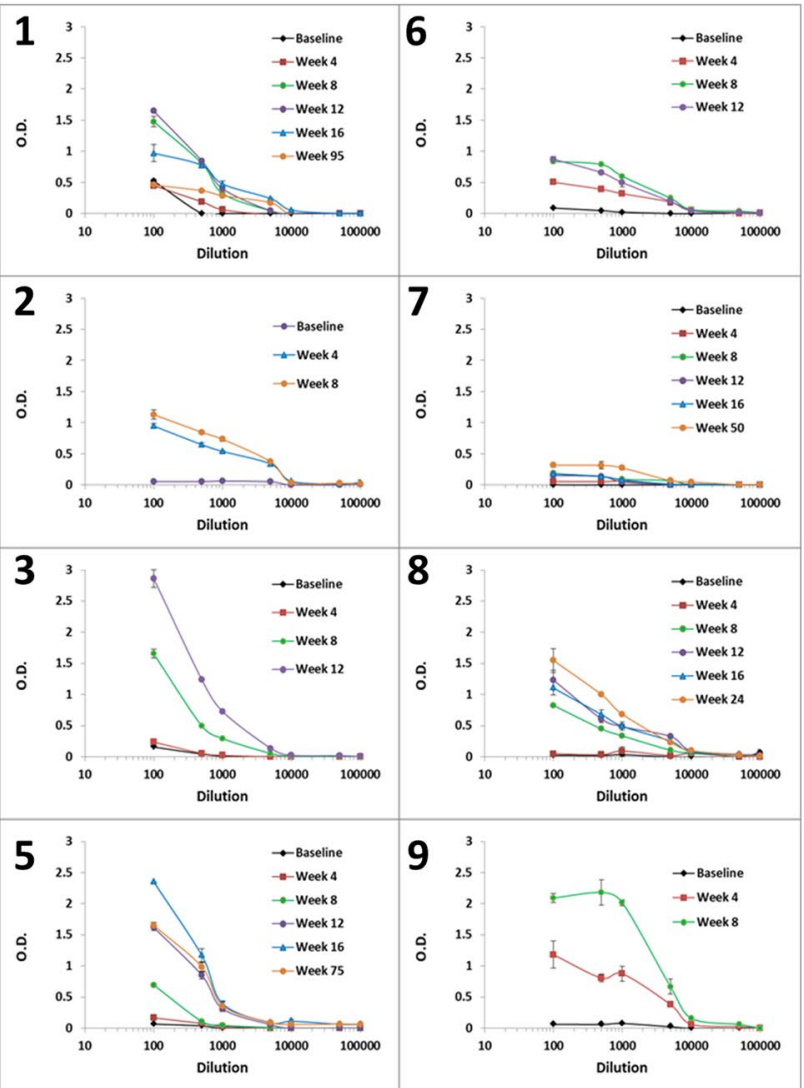

CD8+
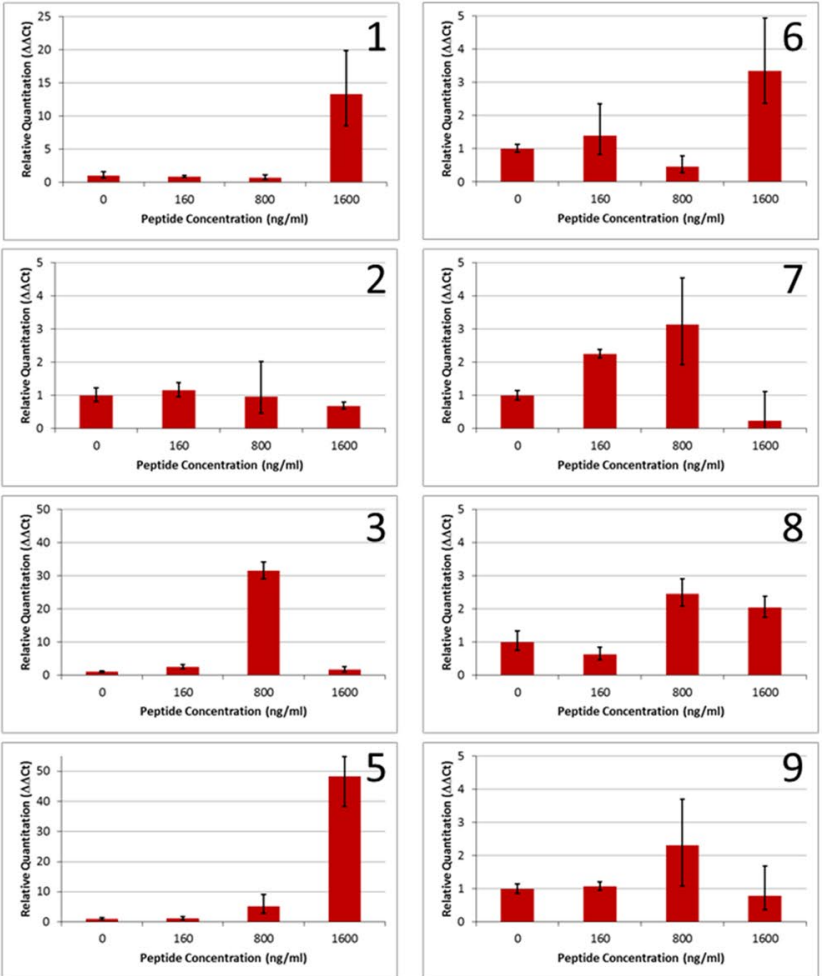
\Fig. 3 Antibodies produced in response to vaccination were measured as a potential biomarker. a IgG antibodies to SVN53-67/M57, and $\mathbf{b}$ IgG antibodies to SVN53-67 were measured in the serum of each patient by ELISA following prime-boost doses, and in those patients who entered an extended dosing phase. Seven patients produced significant levels (>1 O.D.) of SVN53-67/M57 (a) and six patients developed high titers (>1 O.D.) of SVN53-67 antibodies (b). One patient (\#4) was not evaluable due to progression before all four prime-boost doses could be administered. c IFN $\gamma$ mRNA levels in isolated $\mathrm{CD}^{+}{ }^{+}$(left) and $\mathrm{CD}^{+}{ }^{+}$(right) cells from individual vaccinated patients. Cells were stimulated in culture for $2 \mathrm{~h}$ with pooled overlapping survivin peptides (a.a. 53-67) at the indicated concentrations. qPCR of IFN $\gamma$ mRNA was performed as described. Relative quantitation was performed using the $\Delta \Delta C_{\mathrm{t}}$ method, and data were standardized to GAPDH mRNA expression and normalized to IFN $\gamma$ mRNA levels in unstimulated cells. $\mathrm{CD}^{+}{ }^{+}$and $\mathrm{CD} 8^{+}$cell populations were verified to be 94 and $98 \%$ pure, respectively, by FACS analysis (data not shown)

peptide (Fig. 3b) were detected in all evaluable patients with increasing titer over the course of the vaccination series. High titers (>1.0 O.D.) to the survivin vaccine peptide were detected in seven of eight patients. Six of eight patients developed high titers of antibodies that were cross-reactive to the corresponding wild-type survivin peptide. In addition, high titers (>1.0 O.D.) to KLH were detected in four patients and intermediate titers $(>0.75$ but $\leq 1.0$ O.D.) were detected in two patients (data not shown).

\section{Cytokine production in $\mathrm{CD}^{+}$and $\mathrm{CD8}^{+}$cells}

$\mathrm{CD}^{+}$and $\mathrm{CD} 8^{+}$IFN $\gamma$ mRNA levels were measured by qPCR using cells isolated by magnetic bead separation from PBMC obtained at week 12. Depletion of PBMC was confirmed to be $94 \%\left(\mathrm{CD}^{+}\right)$, and $98 \%\left(\mathrm{CD}^{+}\right)$complete by FACS analysis (data not shown). Isolated cells were re-stimulated in culture with pooled overlapping survivin peptides. Induction of IFN $\gamma$ mRNA was detected in $\mathrm{CD} 8^{+}$ cells, but not in $\mathrm{CD}^{+}$cells (Fig. 3c). In general, IFN $\gamma$ mRNA levels increased with higher peptide concentrations up to a maximum tested concentration of $1.6 \mu \mathrm{g} / \mathrm{ml}$.
Fig. 4 FACS analysis of $\mathrm{CD} 8^{+}$ and $\mathrm{CD} 4^{+}$proliferation in CFSE dye-loaded PBMC obtained from two patients (patient \#1; a-d) and (patient \#7; $\mathbf{e}-\mathbf{h}$ ) 12 weeks following vaccination. Proliferation was measured in response to stimulation of cells using either the long (15 amino acid) survivin peptide mimic (SVN53-67/M57) or a 14 amino acid unrelated control peptide (seq: LEEKKQNYVVTDHC). Cell division is indicated by left-shifted peaks

\section{Control}
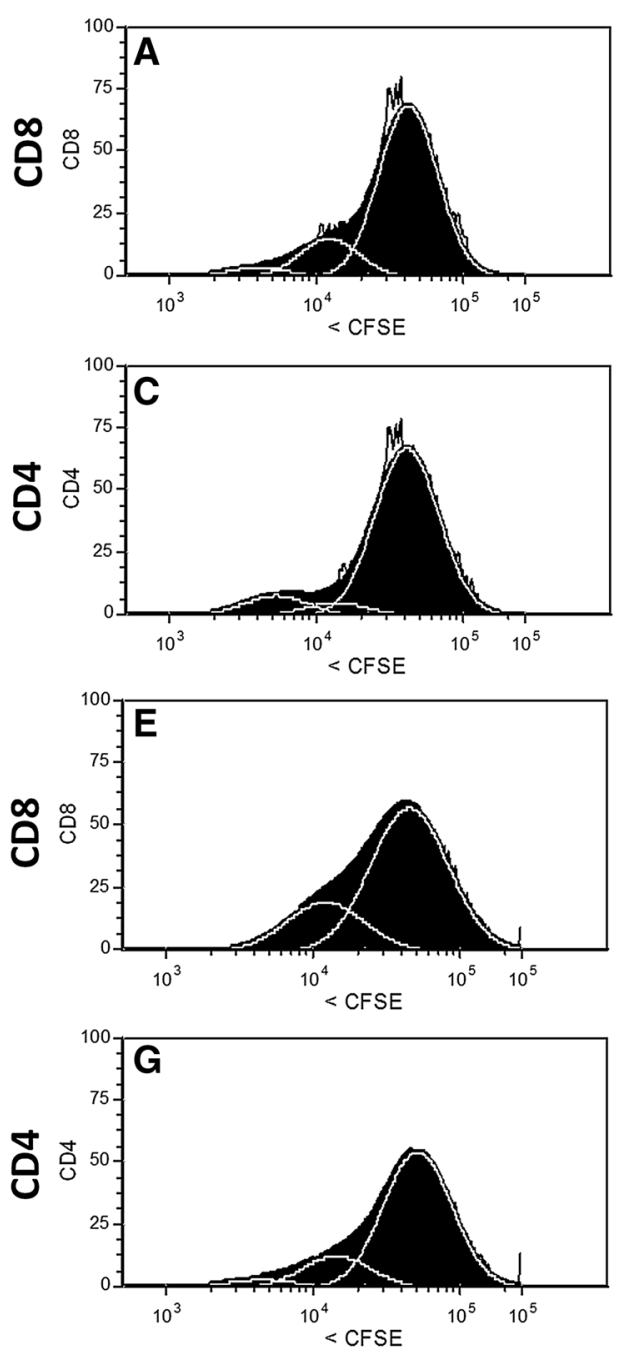

Survivin53-67/M57
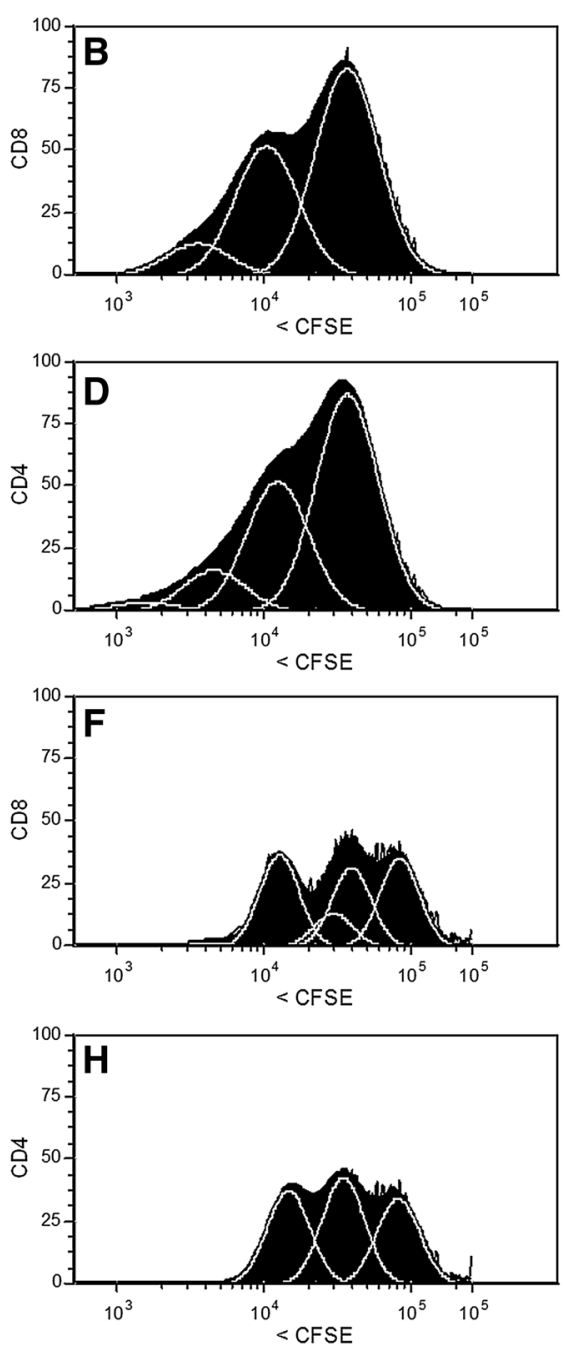


\section{T cell proliferation}

Proliferation of $\mathrm{CD}^{+}$and $\mathrm{CD} 8^{+}$cells in response to ex vivo stimulation with the survivin peptide vaccine was measured by flow cytometry using CFSE-labeled PBMC (Fig. 4). Following co-culture with SVN53-67/M57, both $\mathrm{CD}^{+}{ }^{+}$and $\mathrm{CD}^{+}$cells were stimulated to proliferate, whereas control peptide (irrelevant 14-mer) failed to stimulate proliferation.

\section{Tumor lymphocyte infiltrates}

Three patients with tumor progression following the vaccination regimen underwent biopsy or surgical re-resection of their tumors with histologic evaluation. In all such cases, persistent survivin expression was observed within tumor cells (not shown). Tumors also displayed sparse focal islands of lymphocytes with co-localization of $\mathrm{CD} 4^{+}$, $\mathrm{CD}^{+}$and $\mathrm{CD} 20^{+}$cells resembling lymph node-like germinal center organization (Fig. 5). In addition, small numbers of PD-L1 ${ }^{+}$cells were observed in these regions.

\section{Radiologic response, tumor progression and survival}

One patient with recurrent glioblastoma had a CR and was alive and well with no evidence of disease 174 weeks following the first dose of vaccine. A second patient had a partial radiologic response, but subsequently progressed. Median PFS was 17.6 weeks, and median OS was 86.6 weeks in this study (Fig. 6). One patient (\#5) died of unrelated medical causes with no tumor progression or mass effect (stable disease) documented on MRI scan obtained one week prior to death ( $\mathrm{PFS}=\mathrm{OS}=88$ weeks). Seven of nine patients survived more than 52 weeks following study entry.
Fig. 5 Immunohistochemistry of T and B cell markers $(\times 200)$ in tissue sections of one patient (\#8) with recurrent disease 5.6 months following protocol entry. $\mathbf{a ~ C D} 4^{+}$and $\mathbf{b ~ C D} 8^{+} \mathrm{T}$ cells are shown in representative fields of the patient's glioblastoma prior to vaccine treatment. c $\mathrm{CD} 4^{+}, \mathbf{d ~ C D}^{+}, \mathbf{e ~ C D} 20^{+}$and f PD- $\mathrm{L}^{+}$cells within contiguous histologic sections of tumor after vaccine treatment and subsequent tumor recurrence

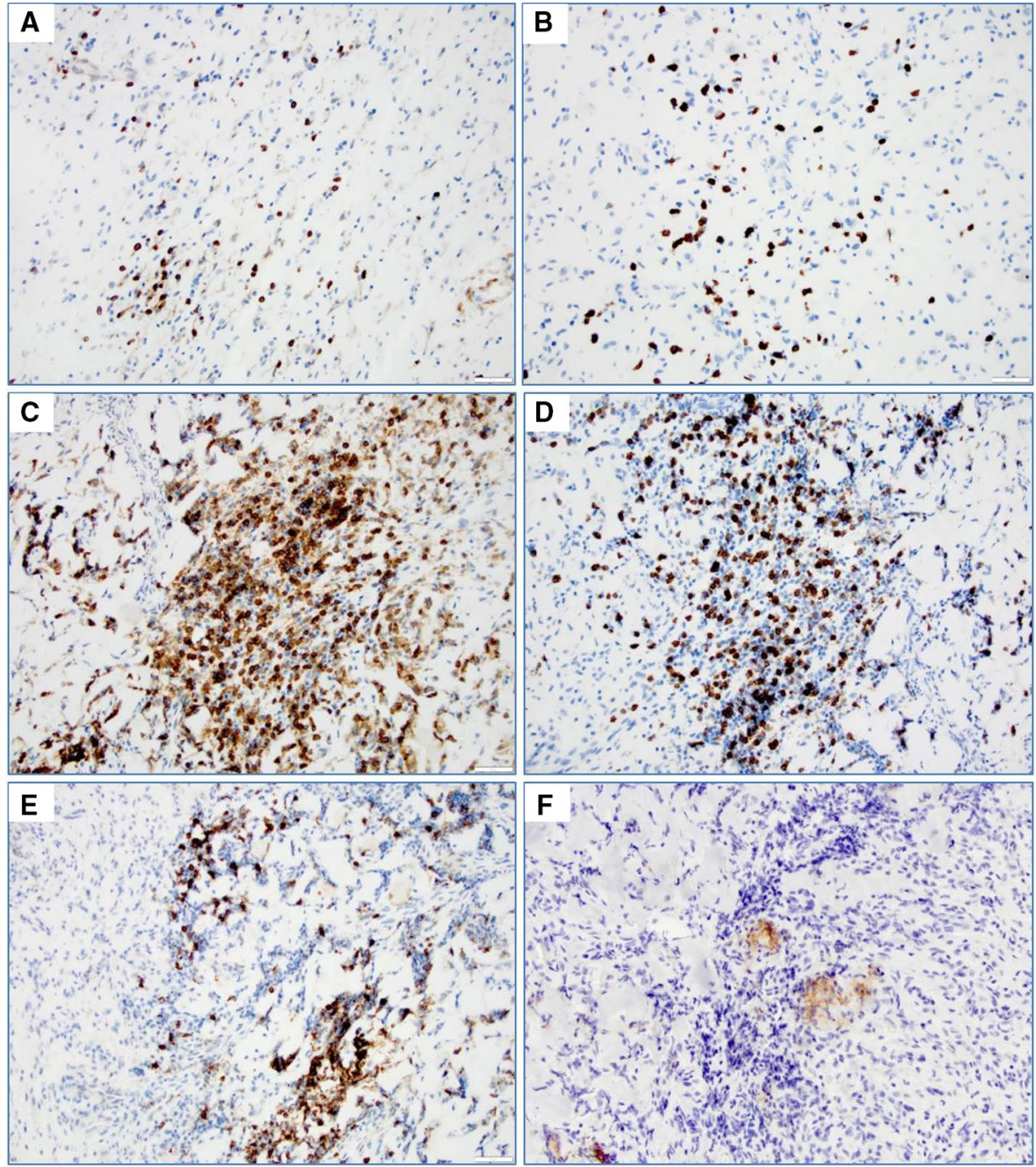


Fig. 6 Progression-free survival (filled triangle) and overall survival (filled square) of patients. Median PFS was 17.6 weeks, and median OS was 86.6 weeks following study entry. MRI showing tumor at diagnosis (left), first recurrence (center) and 42-month follow-up (right)
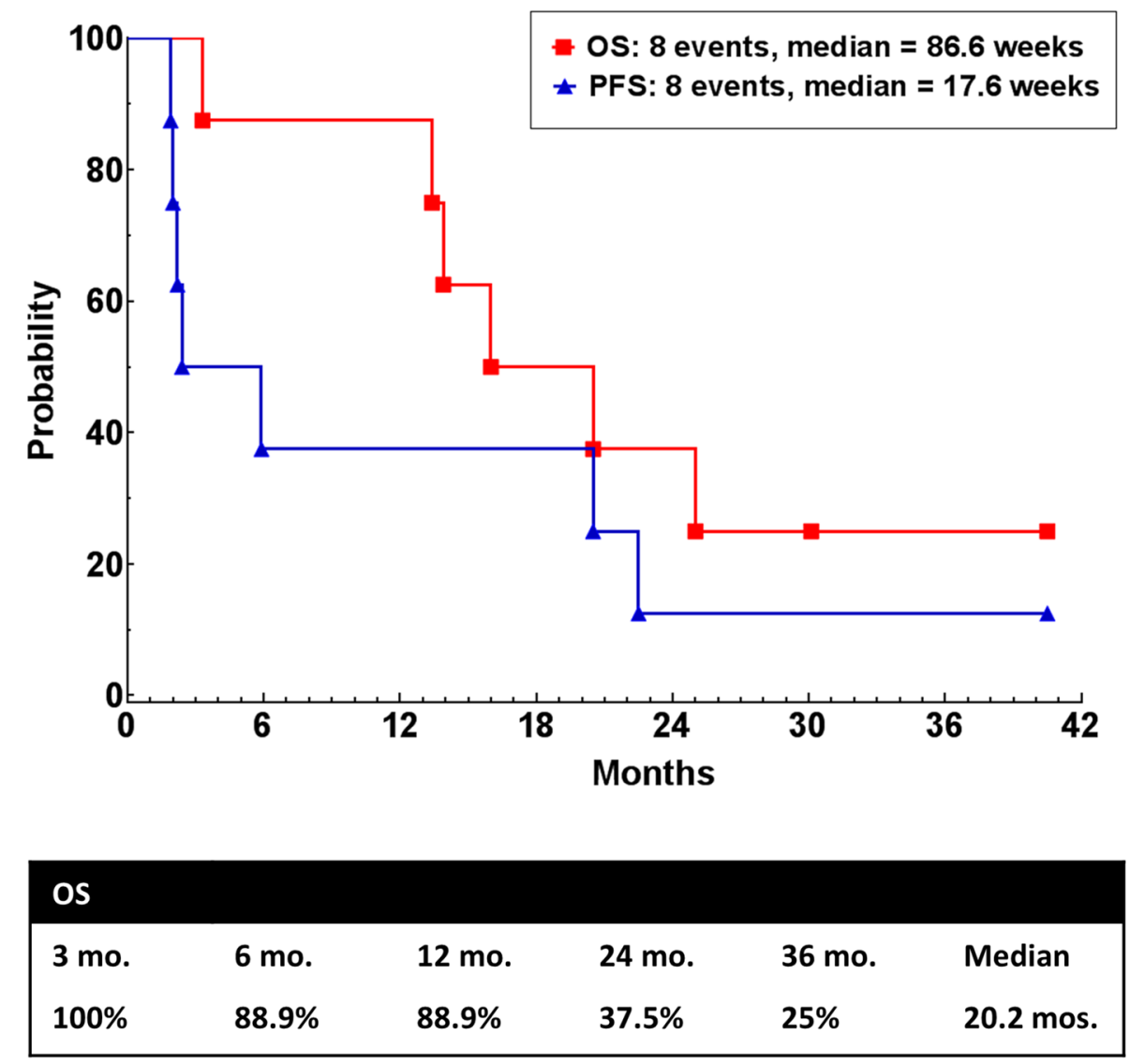

\begin{tabular}{|llllll|}
\hline PFS & & & & & \\
\hline 3 mo. & 6 mo. & 12 mo. & 24 mo. & 36 mo. & Median \\
$50 \%$ & $37.5 \%$ & $37.5 \%$ & $12.5 \%$ & $12.5 \%$ & 4.1 mos. \\
\hline
\end{tabular}

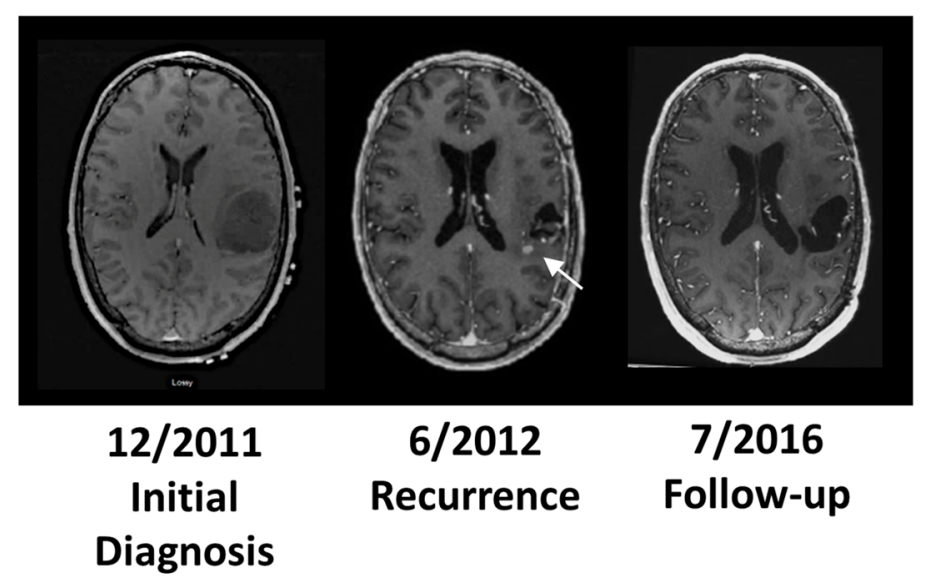

\section{Discussion}

The longest surviving patient in this study had a low but detectable titer of anti-survivin IgG in pre-immune serum. In line with this, previous studies have revealed circulating anti-survivin antibodies in patients with colon and lung cancer $[9,16]$ and in glioma patients as well. Similarly, $\mathrm{T}$ cell reactivity against survivin has been detected in cancer patients in the absence of specific vaccination [17-19]. Therefore, wild-type survivin is at least weakly 
immunogenic and re-stimulation of pre-existing immunity may be one aspect of the vaccine's action.

Clearly, pre-existing anti-survivin immune responses do not completely eliminate tumor cells. We have previously demonstrated that immunologic tolerance to survivin antigens may be broken using molecular mimicry $[11,20]$. SurVaxM contains a synthetic peptide with an amino acid substitution (SVN53-67/M57) that enhances HLA-A*0201 binding acting as a molecular mimic within this contextual background $[11,15,21]$. As a result, the core epitope induces a more potent immune response in humans than the corresponding wild-type survivin peptide [11]. The enhanced binding of SVN53-67/M57 to MHC-I molecules enables it to activate T cells that can cross-react with the wild-type tumor antigens leading to an anti-tumor response [11, 22]. Antigen modification may also aid directly in overcoming $\mathrm{T}$ cell tolerance since patients with non-HLA-A*02 haplotypes (i.e., HLA$\mathrm{A} * 03$, HLA-A*11 and HLA-A*24) also developed $\mathrm{CD} 8^{+} \mathrm{T}$ cell responses to the vaccine in the current study.

The survivin peptide SVN53-67 contains multiple HLA$A * 02$ epitopes, as well as antigen-binding motifs for HLAA*03; HLA-A*11, HLA-A*24, HLA-A*26, HLA-A*68, HLA-B*13, HLA-B*14, HLA-B*15, HLA-B*35, HLA$B * 39$ and HLA-B*44. We have confirmed in this clinical study that HLA-A*02, HLA-A $* 03$ and HLA-A*24 patients generate survivin-specific humoral and cellular immune responses. In pre-clinical studies, we demonstrate that survivin peptide (SVN53-67/M57) stimulated CTL responses against autologous and allogeneic tumor cells from patients with HLA-A*2901, HLA-A*3002 haplotypes [11]. Moreover, in one patient treated under a compassionate use exemption survivin-specific HLA-A*11-restricted CD8 ${ }^{+}$ $\mathrm{T}$ cells were generated in high numbers (data not shown). Consequently, the peptide vaccine is immunogenic in a relatively large segment of the population.

The survivin gene transcript is processed into a number of different mRNA splice variants. All of the various species noted to date retain exon 2 , which encodes the region from which the peptide sequence in SurVaxM is derived. In addition to wild-type survivin, the survivin-2B and survivin- $\Delta \mathrm{Ex} 3$ transcripts, which are translated [23, 24], should also be targeted by immune responses generated by SurVaxM.

We used anti-survivin and anti-KLH IgG levels as a potential biomarker for assessing the immune response to vaccine. Eight patients were evaluable ( $\geq 2$ priming doses) for immune response. Seven had high antibody titers to the survivin vaccine peptide, and 4 had high titers to KLH. Similarly, T cell responses to survivin were seen in seven patients following vaccination. Generally, patients with minimal disease burden had stronger antibody and $\mathrm{T}$ cell responses, although there were too few patients to make a definitive conclusion about the role of bulk disease in systemic immunosuppression. In addition, $\mathrm{CD} 8^{+}, \mathrm{CD} 4^{+}$and $\mathrm{B}$ cell infiltrates were detected in recurrent tumor tissue obtained from patients following progression on-study. In one patient with a germinal center-like structure, PD-L1 was also expressed by adjacent glioma cells, suggesting that PD-1/PD-L1 interaction in the tumor microenvironment could be important for the immune effector response to SurVaxM in some patients [25].

Vaccination strategies utilizing individual $\mathrm{CD}^{+} \mathrm{T}$ cell epitopes alone do not routinely produce significant clinical responses. It is critical to stimulate $\mathrm{CD} 4^{+}$helper T cells simultaneously to potentiate the $\mathrm{CD} 8^{+} \mathrm{T}$ cell-driven antitumor response $[11,15,20,21,26]$. Specific $\mathrm{CD}^{+}{ }^{+} \mathrm{T}$ cell stimulation results in the production of IFN $\gamma$, IL-2 and IL-4 which lead to more robust and sustained CTL activity [27, 28]. The presence of $\mathrm{CD} 4^{+}$support was detected by survivin peptide-induced $\mathrm{CD} 4^{+}$proliferation and can be inferred by the presence of IgM-to-IgG class switching. Generic peptides, such as tetanus, have been used to boost $\mathrm{CD} 4^{+} \mathrm{T}$ cell activity systemically. However, $\mathrm{CD} 4^{+} \mathrm{T}$ cells that are generated through exposure to tumor-associated antigens via antigen presentation on MHC class II are tumor-specific and play a more direct role in the tumor microenvironment [13, 14, 26, 27]. SVN53-67/M57-KLH activates multiple survivin-specific $\mathrm{CD} 8^{+} \mathrm{T}$ cell clones and stimulates survivinspecific $\mathrm{CD}^{+}{ }^{+} \mathrm{T}$ cell proliferation $[11,12,15,21,29]$. Thus, in addition to stimulating $\mathrm{CD} 8^{+}$cellular and antibody-mediated immune responses, SurVaxM may provide important tumor-specific $\mathrm{CD}^{+}{ }^{+}$helper support.

This first-in-human study demonstrated the safety, tolerability and immunogenicity of SurVaxM in patients with recurrent malignant glioma following failure of standard therapy. Progression-free survival was 17.6 weeks, and overall survival was 86.6 weeks. Comparatively, an analysis of eight consecutive phase II chemotherapy trials of patients with recurrent malignant glioma, historical PFS was 10 weeks and historical OS was 30 weeks [30]. Similarly, in a recent phase III clinical trial, which included an arm with physician's choice chemotherapy in patients with recurrent glioblastoma, median PFS was 9 weeks and median OS was 25.7 weeks in the chemotherapy arm [31]. Currently, a larger multi-institutional, phase II clinical trial of SurVaxM plus standard therapy (Stupp protocol) is being conducted in patients with newly diagnosed glioblastoma.

Acknowledgments This project was funded by research grants from: the American Cancer Society RSG-11-153-01-LIB (to M.J. Ciesielski), the American Brain Tumor Association (to N. Yang), the Roswell Park Alliance Foundation, Mr. Philip H. Hubbell and the Linda Scime Endowment. Roswell Park Cancer Institute is supported by National Cancer Institute Cancer Center Support Grant NIH 5P30 CA16056-29. 
Authors' Contributions M.J. Ciesielski and R.A. Fenstermaker were involved in concept and design; M.J. Ciesielski, R.A. Fenstermaker, J. Qiu, N. Yang and A.D. Hutson developed the methodology; M.J. Ciesielski, R.A. Fenstermaker, J. Qiu, L.R. Mechtler and A. Belal acquired the data; M.J. Ciesielski, R.A. Fenstermaker, J. Qiu, A. Belal and A.D. Hutson were involved in the analysis and interpretation of data; R.A. Fenstermaker, M.J. Ciesielski, M. Ahluwalia, K.P. Lee, L.R. Mechtler and J. Qiu wrote, reviewed and/or revised the manuscript; M.J. Ciesielski, R.A. Fenstermaker, C.L. Frank and A.D. Hutson provided administrative, technical or material support (i.e., reporting or organizing data, constructing databases); M.J. Ciesielski, R.A. Fenstermaker and L.R. Mechtler supervised the study.

\section{Compliance with ethical standards}

Conflict of interest R.A. Fenstermaker and M.J. Ciesielski are coinventors on patents regarding SVN53-67/M57-KLH and are cofounders of MimiVax, LLC, which has licensed such patents from Roswell Park Cancer Institute. No additional potential conflicts of interest were disclosed by the other authors.

Open Access This article is distributed under the terms of the Creative Commons Attribution 4.0 International License (http://creativecommons.org/licenses/by/4.0/), which permits unrestricted use, distribution, and reproduction in any medium, provided you give appropriate credit to the original author(s) and the source, provide a link to the Creative Commons license, and indicate if changes were made.

\section{References}

1. Li F, Ambrosini G, Chu EY, Plescia J, Tognin S, Marchisio PC, Altieri DC (1998) Control of apoptosis and mitotic spindle checkpoint by survivin. Nature 396:580-584. doi:10.1038/25141

2. Ambrosini G, Adida C, Altieri DC (1997) A novel anti-apoptosis gene, survivin, expressed in cancer and lymphoma. Nat Med 3:917-921

3. Satoh K, Kaneko K, Hirota M, Masamune A, Satoh A, Shimosegawa T (2001) Expression of survivin is correlated with cancer cell apoptosis and is involved in the development of human pancreatic duct cell tumors. Cancer 92:271-278

4. Kajiwara Y, Yamasaki F, Hama S, Yahara K, Yoshioka H, Sugiyama K, Arita K, Kurisu K (2003) Expression of survivin in astrocytic tumors: correlation with malignant grade and prognosis. Cancer 97:1077-1083. doi:10.1002/cncr.11122

5. Verhaak RG, Hoadley KA, Purdom E et al (2010) Integrated genomic analysis identifies clinically relevant subtypes of glioblastoma characterized by abnormalities in PDGFRA, IDH1, EGFR, and NF1. Cancer Cell 17:98-110. doi:10.1016/j. ccr.2009.12.020

6. Adida C, Crotty PL, McGrath J, Berrebi D, Diebold J, Altieri DC (1998) Developmentally regulated expression of the novel cancer anti-apoptosis gene survivin in human and mouse differentiation. Am J Pathol 152:43-49

7. Uematsu M, Ohsawa I, Aokage T, Nishimaki K, Matsumoto K, Takahashi H, Asoh S, Teramoto A, Ohta S (2005) Prognostic significance of the immunohistochemical index of survivin in glioma: a comparative study with the MIB-1 index. J Neurooncol 72:231-238. doi:10.1007/s11060-004-2353-3

8. Muller L, Muller-Haegele S, Mitsuhashi M, Gooding W, Okada $\mathrm{H}$, Whiteside TL (2015) Exosomes isolated from plasma of glioma patients enrolled in a vaccination trial reflect antitumor immune activity and might predict survival. Oncoimmunology 4:e1008347. doi:10.1080/2162402X.2015.1008347
9. Andersen MH, Pedersen LO, Capeller B, Brocker EB, Becker JC, thor Straten P (2001) Spontaneous cytotoxic T-cell responses against survivin-derived MHC class I-restricted T-cell epitopes in situ as well as ex vivo in cancer patients. Cancer Res 61:5964-5968

10. Altieri DC (2003) Survivin and apoptosis control. Adv Cancer Res 88:31-52

11. Ciesielski MJ, Ahluwalia MS, Munich SA, Orton M, Barone T, Chanan-Khan A, Fenstermaker RA (2010) Antitumor cytotoxic T-cell response induced by a survivin peptide mimic. Cancer Immunol Immunother 59:1211-1221. doi:10.1007/ s00262-010-0845-x

12. Ciesielski MJ, Kozbor D, Castanaro CA, Barone TA, Fenstermaker RA (2008) Therapeutic effect of a T helper cell supported CTL response induced by a survivin peptide vaccine against murine cerebral glioma. Cancer Immunol Immunother 57:18271835. doi:10.1007/s00262-008-0510-9

13. Hung K, Hayashi R, Lafond-Walker A, Lowenstein C, Pardoll D, Levitsky H (1998) The central role of CD4(+) T cells in the antitumor immune response. J Exp Med 188:2357-2368

14. Pardoll DM (1999) Inducing autoimmune disease to treat cancer. Proc Natl Acad Sci USA 96:5340-5342

15. Fenstermaker RA, Ciesielski MJ (2014) Challenges in the development of a survivin vaccine (SurVaxM) for malignant glioma. Expert Rev Vaccines 13:377-385. doi:10.1586/14760584.2014.8 81255

16. Rohayem J, Diestelkoetter P, Weigle B, Oehmichen A, Schmitz M, Mehlhorn J, Conrad K, Rieber EP (2000) Antibody response to the tumor-associated inhibitor of apoptosis protein survivin in cancer patients. Cancer Res 60:1815-1817

17. Hadrup SR, Gehl J, Sorensen RB, Geertsen PF, Straten PT, Andersen MH (2006) Persistence of survivin specific T cells for seven years in a melanoma patient during complete remission. Cancer Biol Ther 5:480-482

18. Yagihashi A, Asanuma K, Nakamura M, Araya J, Mano Y, Torigoe T, Kobayashi D, Watanabe N (2001) Detection of antisurvivin antibody in gastrointestinal cancer patients. Clin Chem 47:1729-1731

19. Reker S, Meier A, Holten-Andersen L, Svane IM, Becker JC, thor Straten P, Andersen MH (2004) Identification of novel survivin-derived CTL epitopes. Cancer Biol Ther 3:173-179

20. Ciesielski MJ, Apfel L, Barone TA, Castro CA, Weiss TC, Fenstermaker RA (2006) Antitumor effects of a xenogeneic survivin bone marrow derived dendritic cell vaccine against murine GL261 gliomas. Cancer Immunol Immunother 55:1491-1503. doi:10.1007/s00262-006-0138-6

21. Ciesielski MJ, Qiu J, Fenstermaker RA (2014) Survivin as a Cancer Vaccine Target. J Vaccines Vaccin. 5:230. doi:10.4172/2157-7560.1000230

22. Overwijk WW, Restifo NP (2000) Autoimmunity and the immunotherapy of cancer: targeting the "self" to destroy the "other". Crit Rev Immunol 20:433-450

23. Fangusaro JR, Jiang Y, Holloway MP, Caldas H, Singh V, Boue DR, Hayes J, Altura RA (2005) Survivin, Survivin-2B, and Survivin-deItaEx 3 expression in medulloblastoma: biologic markers of tumour morphology and clinical outcome. Br J Cancer 92:359-365. doi:10.1038/sj.bjc.6602317

24. Nakano J, Huang C, Liu D, Masuya D, Yokomise H, Ueno M, Haba R, Sumitomo S (2008) The clinical significance of splice variants and subcellular localisation of survivin in non-small cell lung cancers. Br J Cancer 98:1109-1117. doi:10.1038/ sj.bjc. 6604253

25. Castro MG, Baker GJ, Lowenstein PR (2014) Blocking immunosuppressive checkpoints for glioma therapy: the more the merrier! Clin Cancer Res 20:5147-5149. doi:10.1158/1078-0432. CCR-14-0820 
26. Widenmeyer M, Griesemann H, Stevanovic S et al (2012) Promiscuous survivin peptide induces robust $\mathrm{CD} 4^{+} \mathrm{T}$-cell responses in the majority of vaccinated cancer patients. Int $\mathrm{J}$ Cancer 131:140-149. doi:10.1002/ijc.26365

27. Kim EK, Cho HI, Yoon SH, Park MJ, Sohn HJ, Kim HJ, Oh ST, Kim TG (2008) Efficient generation of survivin-specific cytotoxic $\mathrm{T}$ lymphocytes from healthy persons in vitro: quantitative and qualitative effects of $\mathrm{CD}^{+}{ }^{+} \mathrm{T}$ cells. Vaccine 26:3987-3997. doi:10.1016/j.vaccine.2008.05.036

28. Moeller M, Kershaw MH, Cameron R, Westwood JA, Trapani JA, Smyth MJ, Darcy PK (2007) Sustained antigen-specific antitumor recall response mediated by gene-modified $\mathrm{CD}^{+}$ $\mathrm{T}$ helper-1 and $\mathrm{CD}^{+} \mathrm{T}$ cells. Cancer Res 67:11428-11437. doi:10.1158/0008-5472.CAN-07-1141
29. Shen L, Sundstedt A, Ciesielski M et al (2015) Tasquinimod modulates suppressive myeloid cells and enhances cancer immunotherapies in murine models. Cancer Immunol Res 3:136-148. doi:10.1158/2326-6066.CIR-14-0036

30. Wong ET, Hess KR, Gleason MJ, Jaeckle KA, Kyritsis AP, Prados MD, Levin VA, Yung WK (1999) Outcomes and prognostic factors in recurrent glioma patients enrolled onto phase II clinical trials. J Clin Oncol 17:2572-2578

31. Stupp R, Wong ET, Kanner AA et al (2012) NovoTTF-100A versus physician's choice chemotherapy in recurrent glioblastoma: a randomised phase III trial of a novel treatment modality. Eur J Cancer 48:2192-2202. doi:10.1016/j.ejca.2012.04.011 